\title{
Evaluating Company's Maintenance Strategy Effectiveness by Maintenance Improvement Index - A Case Study
}

\author{
Damjan Maletič ${ }^{1 *}$, Matjaž Maletič ${ }^{1}$, Boštjan Gomišček ${ }^{2}$ \\ 1 Faculty of Organizational Sciences, University of Maribor, Slovenia \\ ${ }^{2}$ Faculty of Business, University of Wollongong in Dubai, UAE
}

\begin{abstract}
The purpose of this paper is to present development of a methodology for identifying improvement areas and supporting decision making process in the field of maintenance; an index for measuring the performance level of different maintenance approaches is proposed. Empirical data for this case study was drawn from a Slovenian textile company. The results of this study indicate that from respondents' points of view, maintenance practices related to condition-based maintenance approach represent the highest opportunity for improvements in this company. Further, this study provides key insights for managers to evaluate maintenance approaches, and to identify potential areas for improvements. In this regard, companies can gain a better understanding of how to measure and diagnose the effectiveness of the selected (implemented) maintenance strategy. As such, the presented work provides an intuitive and simple approach to identify the areas where a company effectively deploys its resources, and those areas that need more attention. Presented approach therefore represents an effective way of selecting areas for improvements for companies searching an approach how to improve effectiveness of maintenance strategy, and therefore company's competitiveness.
\end{abstract}

Keywords: maintenance, strategy, gap analysis, effectiveness, competitiveness, maintenance improvement index

\section{Introduction}

Increasing expansion of technology and competition among industries are one of the drivers forcing organizations to employ different strategies and policies to increase productivity and decrease costs [1]. Manufacturing companies face a great pressure to reduce their production costs [2]. The costs of maintenance are estimated to be between 15 and 40 per cent of production costs [3]. In this regard, different maintenance policies and strategies are implemented in production industries to decrease costs, increase productivity and to continue with the global competition [1].

A number of studies have been devoted to identify the impact of maintenance on different dimensions of company's competitiveness. For instance, in study [4] author found a positive relationship between proactive and aggressive maintenance strategies and maintenance performance. Results of study [5] showed that total productive maintenance does more than control costs; it can improve dimensions of cost, quality, and delivery. Al-Najjar and Alsyouf [6] indicated that a company can increase its production capacity without investing in new machinery if it 
implements an efficient maintenance policy, which allows enhancing availability strongly, quality rate and performance efficiency moderately. In their study authors have presented a model to provide the required information for decision-making, to ensure cost-effective actions and enhance continual improvement efforts cost-effectively. Further, Al-Najjar [7] suggested that by applying effective maintenance, such as Total quality maintenance (TQMain), a company's profitability and competitiveness can be enhanced through the continuous cost-effective improvement of production and maintenance processes. In other words, the better the knowledge we have about the interaction between maintenance and other business variables, the better our decisions [8]. This means, that proper management of maintenance can offer many companies significant potential of improving efficiency, productivity and profitability [9].

In study [10], author reported that the mean percentage of overall equipment effectiveness (OEE) across the sampled cases, was 55 percent. This means that company could increase its production capacity without investing in new machinery if an efficient maintenance policy was implemented [6]. Using effective maintenance policies, failures can be reduced to a minimum level [11]. This could result in higher productivity and better product quality and nevertheless in higher profit margin.

Different methods are available for measuring the state of maintenance practices in companies. Maturity assessment methods are one of the examples used to assess how maintenance processes are conducted. For example, Macchi and Fumagalli [12] proposed a scoring method for maturity assessment and a procedure to use it in order to identify the criticalities in maintenance processes and to subsequently drive the improvement of the maintenance management system. Further, Chemweno et al. [13] suggested a generic asset maintenance maturity model as a structured guide for implementing new maintenance programs, evaluating existing programs and finally directing continuous improvement activities likely to lead to high levels of asset maintenance efficiency and effectiveness. Further, researchers (e.g. [14]) used benchmarking as a way to search for optimum methods for maintenance management practices in order to improve the overall effectiveness of the operations and maintenance of the plant. Although there is a growing body of literature on different methods for evaluation maintenance effectiveness, there is still lack of studies that would propose approaches for identifying and prioritizing improvement areas. Hence, a company requires to assess the current quality of the maintenance management system before deciding an investment for its improvement [12]. Given the above reasons, this paper presents a case study with the following objectives: to examine the performance and importance of different maintenance practices from respondents' points of view, and to identify the areas where company can improve efficiency and effectiveness of its maintenance strategy. Thus, the purpose of this study is to propose new methodology which can support the process of exploring and identifying the areas where company has effectively deployed their resources, and those that need more attention. Evaluating the performance of maintenance strategies using different measures has been a major concern in maintenance operations literature [15]. A number of techniques and frameworks have been developed in this field. Nonetheless, this study also contributes to the literature by providing a new measure for identifying and assessing potential areas for improvement in relation to the maintenance strategy.

\section{Literature review}

\subsection{Maintenance approaches}

Several maintenance approaches, i.e. strategies and concepts, methodologies or philosophies have been developed and implemented through the evolution of maintenance. The traditional perception of maintenance's role is to fix broken items. Taking such a narrow view, maintenance activities have been confined to the reactive tasks of repair actions or item replacement [16]. More recently, improved technology and the increased sophistication of maintenance personnel have led some companies to replace this type of approach with different maintenance strategies [4]. The description of various maintenance concepts is explained below:

Failure based maintenance (FBM): FBM is only performed when a failure or breakdown occurs [6]. Therefore, FBM is a reactive management technique that waits for machine or equipment failure before 
any maintenance action is taken; however, it is actually a "no-maintenance" and the most expensive approach of management [17]. Nonetheless, it is always possible that a failure is allowed to occur and then be repaired. This depends on the existence of secondary damage, redundancy and the ease to repair. In the case of technical feasibility of FBM for a critical component or a non-critical component, the economic feasibility must be determined [18].

Preventive maintenance (PM):PM can be described as a series of tasks performed at a frequency dictated by the passage of time, the amount of production, machine condition that either extend the life of an asset or detect that an asset had critical wear and is going to fail or break down constitute PM [19]. In maintenance management, there are two classical strategies: block-based (also called constant-interval maintenance) and age-based (also called use-based maintenance) maintenance [18]. One of the disadvantages of the PM is that PM is only economical where the standard deviation of the failure population is small [20]. The other critical aspects considering PM are the lack of decision support systems and insufficient historical data [21], [22].

Condition-based maintenance (CBM): CBM is a maintenance program that recommends maintenance decisions based on the information collected through condition monitoring [23]. Maintenance decision is made depending on the measured data from a set of sensors system when using the condition-based maintenance strategy. To date a number of monitoring techniques are already available, such as vibration monitoring, lubricating analysis, and ultrasonic testing [2]. However, if the condition of the item can be monitored continuously or intermittently it will be possible to carry out PM actions only when failure is judged to be imminent [24].

Reliability-centered maintenance (RCM): $\mathrm{RCM}$ was originally designed for the aircraft industry [25]. There have also been several improvements to the traditional RCM methodology for different applications, e.g. RCM2 [26]. RCM combines several well known risk management techniques and tools, such as failure mode and effect analysis and decision trees, in a systematic approach to support effective and efficient maintenance decision [27]. Because RCM is predicted on the belief that all machines will degrade and fail (P-F curve), most of the task, such as failure modes and effects analysis (FMEA) and Weibull distribution analysis, are used to anticipate when these failures will occur [17].

Total productive maintenance (TPM): TPM is a maintenance system defined by [28], which covers the entire life of equipment and involves active participation of every division including planning, manufacturing, and maintenance. Therefore, TPM seeks to engage all levels and functions in a company to maximize the overall effectiveness of production equipment [16]. The emergence of TPM is intended to bring both production and maintenance functions together by a combination of good working practices, team-working and continuous improvement [29]. However, some shortcomings are observed in the literature as discussed in the following. First, TPM does not provide clear rules to decide which basic maintenance policy will be used, and second calculation of the OEE is not really a complete analysis. Cost and profits are not taken into account, and therefore it is not a complete measure [18].

Total Quality Maintenance (TQMain): TQMain is a strategy which enables the user to maintain and improve continuously the technical and economic effectiveness of process elements. Thus, TQMain's role may be defined as: a means for monitoring and controlling deviations in a process condition and product quality, and for detecting failure causes and potential failures in order to interfere when it is possible to reduce machine deterioration rate before the product characteristics are intolerably affected and to perform the required action to restore the machine/process or a particular part of it to good as new. It suggests the integration of the separate relevant databases of the manufacturing system into a common data-base and uses a reconstructed version of OEE, which is called overall process effectiveness (OPE) [7].

\subsection{Maintenance strategy selection}

A number of empirical studies that focused on maintenance strategy selection have been reported in the literature. Azadivar and Shu [30] showed some effective methods of selecting appropriate maintenance strategies for just in time production systems. Okumura and Okino [31] presented the maintenance selection method based on production loss and maintenance cost. Bevilacqua and Braglia [32] used an analytical hierarchy process (AHP) for maintenance selection in an oil refinery. 
Maletič et al. [33] apply AHP for the evaluation/ selection of maintenance policy. Many different multiple criteria decision-making (MCDM) methods were also adopted in maintenance strategy selection. For example, Al-Najjar and Alsyouf [22] assessed the most popular maintenance strategies using the fuzzy inference theory and fuzzy MCDM evaluation methodology. Wang et al. [2] evaluated maintenance strategies based on the fuzzy AHP method. In astudy [34] authors proposed a combined goal programming and AHP for maintenance selection through the use of the classic parameters occurrence, severity and detectability. Further, Ingwald and Al-Najjar [35] emphasized the need of selecting the most cost-effective maintenance for a certain component/equipment. While there is a great body of knowledge on maintenance strategy selection, our study is more focused on assessing the maintenance strategy aiming to identify the potential areas for improvements.

\section{A methodology for identification of maintenance improvement opportunities}

This section will discuss how it may be possible to measure and identify improvement opportunities in the maintenance processes. The methodology will be explained by using data from a Slovenian textile company.

The basic idea behind the approach used in this case study, is to measure importance and performance of different maintenance practices [36]. By identifying the gaps considering maintenance practices in a company, it is possible to explore areas where company has effectively deployed their resources and those that need more attention. For purpose of this study questionnaire was prepared, in order to evaluate importance and performance of different maintenance activities in the observed company. Due to the company's request for confidentiality, the name of the company is not disclosed in this text. Respondents in this study were employees $(N=5)$ from production department (maintenance function is a part of production department). While interviewing with the help of a questionnaire, respondents were asked to rank each question, formulized as statements, according to their perceived degree of agreement and importance using the Likert scale ranging from 1 to 5 . On the "importance" scale, "1" indicates that the statement according to him/her is of very minor importance, while statements that score " 5 " are perceived as having very high importance. Generally, the importance measurements (I) can be understood as indications of the respondents needs and the agreement measurements (A) as indications of the company's performance. These measurements ( $I$ and $A$ ) are the basis for the calculation of maintenance improvement (MI) index presented in section 4.

The most important areas are related to the statements where the difference between importance and agreement is the highest. The theory behind such type of questionnaire is that the optimal situation is characterised by having equality between importance and agreement. An assumption behind this simple rule is that the marginal costs to reduce the gaps with one unit are the same for all statement areas. Of course, this assumption is a simplification because some areas may be easier to improve than the other areas [37]. If one can accept the simplified assumption, then the simplified rule can be used. That means if importance is significantly higher than agreement one should improve the area.

Additionally, using this methodology one can figure out by using the scores for importance which maintenance practice is rated as the most important one, as well.

Thus, knowing these two parameters, the prioritization and the difference, one can very easily define the practices/areas where the most effort should be put in to improve the current situation.

\subsection{Measures}

Ten practices were examined in this study. These practices were derived from literature focusing on maintenance practices (e.g. [4]; [38]). The strategic approach focuses mainly on spare parts and repair times. Process-oriented approach includes practices related to production process. CBM approach comprises practices, such as condition monitoring, activities of detecting failure causes as well as the use of computerized maintenance management systems (CMMS).

\section{Measuring maintenance improvement (MI) index}

As revealed in section 3 the idea of asking the respondents both about agreement and importance is that by doing so, it is possible to rank the potential areas for improvements in accordance 
with the respondents' importance perceptions [39]. This paper expands the gap analysis presented in study [36] by developing an indicator for measuring maintenance improvement (MI) index. In this section, we will discuss a new approach and present the $\mathrm{Ml}$ index using data for different maintenance approaches.

In order to evaluate maintenance strategy and to identify the potential areas for improvement, analysis of perceived agreement and perceived importance scores was performed. Any difference between perceived indicated agreement and perceived importance $(I-A)$ can be regarded as a gap indicating an opportunity for improvement seen from the respondents' points of view [39]. By using this approach, gaps between importance and agreement represent the signals from the respondents regarding possible improvement opportunities. As shown in Figure 1 (a detailed description of items is presented in Table 1), the biggest gap between importance and agreement refers to the practices such as monitoring the production equipment status (item 5), investing in improving the skills and competence of maintenance staff (item 1) and performing the maintenance tasks based on statistical modelling of failure data (item 2).

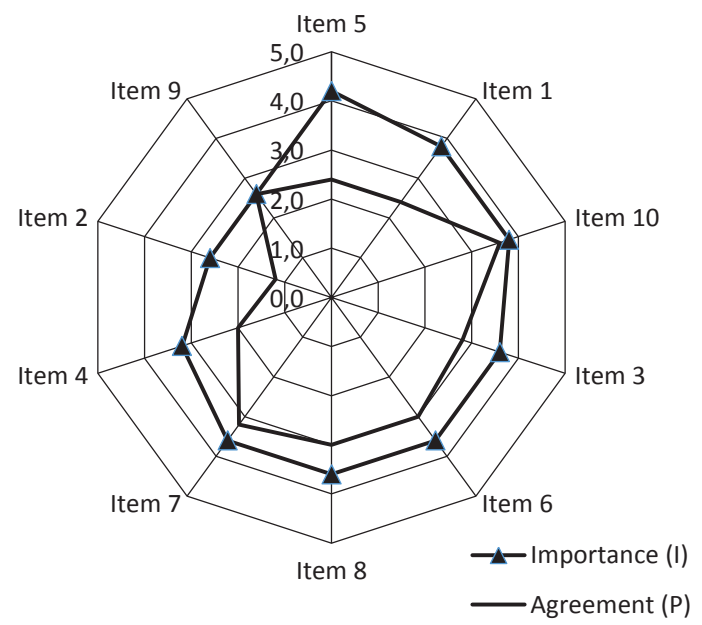

Fig. 1: Identification of statements with the biggest gaps.

The results for importance and performance statements illustrated in Figure 1 show that the biggest gaps correspond to practices that describe the CBM approach.

The proposed measure (MI index) is based on the same data as for the gap analysis presented in Figure 1. First we merged a set of ten maintenance practices into three main themes. Each of the themes consists of the practices that have a common underlying dimension. As such, we followed the literature (e.g. [38]) in order to ensure content validity. Note that it is possible to include any additional maintenance practices when using this methodology. MI index uses the ratio of average agreement and average importance. The simple logic behind this measure is however similar to approach presented in study [39]. The calculated measures range between zero and one $\{0 ; 1.0\}$. If the measure is close to 1.0 then it indicates that the company has effectively deployed their resources within the areas measured. On the contrary if the measure is low this represents the signals for company to look for improvements within the measured area. In our example, the lowest MI index corresponds to the first main theme (0.63), as shown in Table 1. This represents the highest potential for improvement (up to 37 percent) of all three measured themes.

Table 1: Maintenance improvement index

\begin{tabular}{|c|c|c|}
\hline First main theme & Importance & Agreement \\
\hline $\begin{array}{l}\text { Item 1: Investing in improving the skills and } \\
\text { competence of maintenance staff }\end{array}$ & 3.8 & 2.4 \\
\hline $\begin{array}{l}\text { Item 2: Performing the maintenance tasks } \\
\text { based on statistical modelling of failure data }\end{array}$ & 2.6 & 1.2 \\
\hline $\begin{array}{l}\text { Item 3: Analysing equipment failure causes } \\
\text { and effects }\end{array}$ & 3.6 & 2.8 \\
\hline $\begin{array}{l}\text { Item 4:Use of computerized maintenance } \\
\text { management systems (CMMS) }\end{array}$ & 3.2 & 2.0 \\
\hline $\begin{array}{l}\text { Item 5: Monitoring the production equipment } \\
\text { status }\end{array}$ & 4.2 & 2.4 \\
\hline Averages & 3.5 & 2.2 \\
\hline MI index: & $2.2 / 3.5=0.63$ & \\
\hline Second main theme & Importance & Agreement \\
\hline $\begin{array}{l}\text { Item 6: Keeping the level low in spare parts } \\
\text { inventory }\end{array}$ & 3.6 & 3.0 \\
\hline Item 7: Decreasing the repair time & 3.6 & 3.2 \\
\hline Averages & 3.6 & 3.1 \\
\hline MI index: & $3.1 / 3.6=0.86$ & \\
\hline Third main theme & Importance & Agreement \\
\hline $\begin{array}{l}\text { Item } 8 \text { : Helping improve the production } \\
\text { process }\end{array}$ & 3.6 & 3.0 \\
\hline $\begin{array}{l}\text { Item 9: Performing periodic planned } \\
\text { replacement }\end{array}$ & 2.6 & 2.6 \\
\hline Item 10: Recording process quality rate & 3.8 & 3.6 \\
\hline \multirow[t]{2}{*}{ Averages } & 3.3 & 3.1 \\
\hline & $3.1 / 3.3=0.93$ & \\
\hline
\end{tabular}


As shown in Table 1 one can see that the Ml index for the second main theme is equal to 0.86 , which means that the company should look for improvements within these practices where up to 14 percent could be reached with proper improvement actions. MI index for the third main theme was calculated to 0.93 , which means that company could increase this measure up to 7 percent.

In our case, the assumption is that all approaches have the same importance. This mean that practices which correspond to the first main theme represent the biggest potential area for improvements in accordance with the respondents' perceptions. As seen in Table 1 these practices are mostly associated with CBM approach.

\section{Discussion}

The importance performance analysis and MI index exhibits several findings, which deserve further attention. First, among the ten observed practices included in this study, CBM approach allows for the biggest opportunity for improvement. This finding reflects the difference of the importance of maintenance practices from a company's perspective. Further analysis reveals that company is not using advanced maintenance approaches and that there is still high portion of failure based maintenance. The main tasks conducted considering maintenance are, for instance: restoring equipment to operation, installing new equipment, etc. Moreover, the proposed MI index clearly reveals that statements within the CBM approach represent the lowest measure. Thus, the company should look for improvements within these practices - the $\mathrm{Ml}$ index could be gradually improved with up to 37 percent. The results show that the biggest gaps correspond to practices, such as monitoring the production equipment status, performing the maintenance tasks based on statistical modelling of failure data, investing in improving the skills and competence of maintenance staff and use of CMMS. These maintenance practices are related to CBM approach, and represent the biggest potential area for improvements in accordance with the respondents' importance perceptions. Therefore, the combination of the highest importance and the biggest gaps represent the signals from the respondents about where to improve first. As we have already mentioned above, we observed that the lowest MI index correspond to CBM approach. Several studies [6], [11], [22], [36] emphasize the importance of CBM in achieving company's profitability and competitiveness. By improving the areas which have received the lowest $\mathrm{MI}$ index company could benefit from higher quality and productivity. Several studies have shown that proper maintenance can lead company to a better product quality and higher productivity. For example, the study [40] has shown that maintenance has an impact on the production and its operational aspects such as capacity, quality, costs, environment and safety. Therefore, the results indicate that company should look for improvements within CBM approach in order to improve productivity, quality, profitability and nevertheless the overall competitiveness. In this regard, our results imply that activities within CBM approach are essential in order to enhance the performance of the production process.

Our results are also somewhat in a line with the argument of Crespo Márquez et al. [41] who suggest that higher levels of knowledge, experience and training is required, and at the same time, techniques covering the involvement of operators in performing simple maintenance tasks are extremely important to reach higher levels of maintenance quality and overall equipment effectiveness. Similarly, as it was outlined by Pacaiova et al. [42], who stated that the problem of effective management, particularly in terms of demands for continuous improvement is often a lack of information and knowledge on the management level. Further, Berges et al. [43] noted in their study that the human factor in the maintenance function is an essential factor involved in the performance of this department. Authors also pointed out that despite technological improvements in the conservation of machines, the human element remains essential to the quality of the work performed. Therefore, it can be argued that by improving the level of knowledge and experience, the company could improve the effectiveness of maintenance strategy. Human factors are therefore important aspects to be considered in the field of maintenance [44].

From the managerial perspective, this study emphasizes the importance of implementing effective maintenance policy. The results provide insights on the status of several maintenance practices in the observed company. The results have shown that according to respondent's point of view 
the CBM approach could be the primary source of competitive advantage. This is consistent with the current literature, which suggests that companies could improve and maintain their competitiveness if more effective maintenance and asset management would have been used [45] - [47]. The proposed MI index also represents a practical value for managers. For a company that is looking for improvements within the maintenance processes, it is important to select the most appropriate maintenance policy. In this regard, the proposed index supports the decision-making process. In addition, this new measure presented in this paper can be used by all types of organizations, and could include several different maintenance practices.

\section{Conclusions}

This paper presents an empirical study that examines maintenance practices in a Slovenian textile company. The gap analysis based on respondent's perception regarding agreement and importance of selected maintenance practices was performed. In addition, a new measure (MI index) for identifying areas that company should focus on was proposed. The results provide a clear result that company should put more effort in improving the practices related to the CBM approach. Therefore, the insights drawn from this study could help the company to balance their priorities and suggest the areas on which emphasis should be placed. Further, the case study demonstrated that in searching competitiveness through efficient maintenance strategy, the $\mathrm{Ml}$ index provides a company with a tool for selecting and setting priorities for improvement of different practices within the field of maintenance. Therefore, this methodology enables:

- the use of employee's perceptions regarding the degree of agreement and importance of different maintenance practices,

- the use of the MI index, a new measure which compares importance with agreement in implicitly setting improvement priorities and nevertheless

- companies can also use the MI index as a benchmarking for trend analysis and setting the objectives as a part of their planning and improving process as well as

- to measure and diagnose the effectiveness of the selected maintenance strategy.

Although this study contributes to both academia and practice, we acknowledge some limitations that open up avenues for further research. For instance, our constructs of maintenance practices did not cover all aspects of different maintenance strategies - other studies should therefore focus on several additional maintenance practices.

\section{References and Notes}

[1] Gupta, G., Mishra, R. P. (2016). A SWOT analysis of reliability centered maintenance framework. Journal of Quality in Maintenance Engineering, 22, 130-145. doi:10.1108/JQME01-2015-0002

[2] Wang, L., Chu, J., Wu, J (2007). Selection of optimum maintenance strategies based on a fuzzy analytic hierarchy process. International Journal of Production Economics, 107(1), 151-163.

[3] Dunn, R. (1987). Advanced maintenance technologies. Plant Engineering, 40(12), 80-2.

[4] Swanson, L. (2001). Linking maintenance strategies to performance. International Journal of Production Economics, 70(3), 237-244.

[5] McKone, K.E., Schroeder, R.G., Cua, K.O. (2001). The impact of total productive maintenance practices on manufacturing performance. Journal of Operations Management, 19(1), 39-58.

[6] Al-Najjar, B., Alsyouf, I. (2004). Enhancing a company's profitability and competitiveness using integrated vibration-based maintenance: a case study. European Journal of Operational Research, 157(3), 643-657.

[7] Al-Najjar, B. (1996). Total quality maintenance: an approach for continuous reduction in costs of quality products. Journal of Quality in Maintenance Engineering, 2(3), 4-20.

[8] Komonen, K. (2002). A cost model of industrial maintenance for profitability analysis and benchmarking. International journal of production economics, 79, 15 - 31.

[9] Löfsten, H. (1999). Management of industrial maintenanceeconomic evaluation of maintenance policies. International Journal of Operations \&Production Management, 19(7), 716-737.

[10] Ljungberg, O. (1998). Measurement of overall equipment effectiveness as a basis for TPM activities. International Journal of Operations and Production Management, 18(5), 495-507.

[11] Alsyouf, I. (2007). The role of maintenance in improving companies' productivity and profitability. International Journal of Production Economics, 105(1), 70-78.

[12] Macchi, M., Fumagalli, L. (2013). A maintenance maturity assessment method for the manufacturing industry. Journal of Quality in Maintenance Engineering, 19(3), 295-315

[13] Chemweno, P., Pintelon, L., Horenbeek, A. V., Muchiri, P. N. 
(2015). Asset maintenance maturity model: structured guide to maintenance process maturity. International Journal of Strategic Engineering Asset Management, 2(2), 119135.

[14] Richard, C. M., Tse, P., Ling, L., Fung, F. (2000). Enhancement of maintenance management through benchmarking. Journal of Quality in Maintenance Engineering, 6(4), 224240.

[15] Kumar, U., Galar, D., Parida, A., Stenström, C., Berges, L. (2013). Maintenance performance metrics: a state-of-the-art review. Journal of Quality in Maintenance Engineering, 19(3), $233-277$.

[16] Ahuja, I.P.S., Khamba, J.S. (2008). An evaluation of TPM initiatives in Indian industry for enhanced manufacturing performance. International Journal of Quality \& Reliability Management, 25(2), 147-172.

[17] Mobley, R.K. (2002). An introduction to predictive maintenance. Butterworth-Heinemann; 2 edition, USA.

[18] Waeyenbergh, G., Pintelon, L. (2002). A framework for maintenance concept development. International Journal of Production Economics, 77(3), 299-313.

[19] Garg, A., Deshmukh, S.G. (2006). Maintenance management: literature review and directions. Journal of Quality in Maintenance Engineering, 12(3), 205 - 238.

[20] Mann, L., Saxena, A., Knapp, G. (1995). Statistical-based or condition-based preventive maintenance? Journal of Quality in Maintenance Engineering, 1(1), 46-59.

[21] Dekker, R. (1996). Applications of maintenance optimization models: a review and analysis. Reliability Engineering and System Safety, 51(3), 229-240.

[22] Al-Najjar, B., Alsyouf, I. (2003). Selecting the most efficient maintenance approach using fuzzy multiple criteria decision making. International Journal of Production Economics, 84(1), 85-100.

[23] Jardine, A.K.S., Lin, D., Banjevic, D. (2006). A review on machinery diagnostics and prognostics implementing condition-based maintenance. Mechanical Systems and Signal Processing, 20(7), 1483-510

[24] Tsang, A.H.C. (2002). Strategic dimensions of maintenance management. Journal of Quality in Maintenance Engineering, 8(1),7-39.

[25] Nowlan, F.S., Heap, H.F. (1978). Reliability Centered Mainteance, United Airlines Publications, San Fransisco.

[26] Moubray, J. (1997). Reliability-centered maintenance, 2nd ed., Industrial Press Inc, New York.

[27] Backlund, F., Akersten, P.A. (2003). RCM introduction: process and requirements management aspects. Journal of Quality in Maintenance Engineering, 9(3), 250-264.

[28] Nakajima, S. (1988). Introduction to Total Productive Maintenance. TPM. Productivity Press, Cambridge.
[29] Cooke, F.L. (2000). Implementing TPM in plant maintenance: some organisational barriers. International Journal of Quality \& Reliability Management, 17(9), 1003-1016.

[30] Azadivar, F., Shu, V. (1999). Maintenance policy selection for JIT production systems. International Journal of Production Research, 37(16), 3725-38.

[31] Okumura, S., Okino, N. (2003). A maintenance policy selection method for a critical single-unit item in each workstation composing a FMS with CBM optimization. International Journal of COMADEM, 6(2), 3-9.

[32] Bevilacqua, M., Braglia, M. (2000). The analytic hierarchy process applied to maintenance strategy selection. Reliability Engineering and System Safety, 70(1), 71-83.

[33] Maletič, D., Maletič, M., Lovrenčić, V., Al-Najjar, B., \& Gomišček, B. (2014). An application of analytic hierarchy process (AHP) and sensitivity analysis for maintenance policy selection. Organizacija, 47(3), 177-188.

[34] Bertolini, M. and Bevilacqua, M. (2006). A combined goal programming - AHP approach to maintenance selection problem. Reliability Engineering and System Safety, 91(7), 839-848.

[35] Ingwald, A., Al-Najjar, B. (2012). Selecting and improving a maintenance policy for mechanical components using cost-effectiveness. International Journal of Strategic Engineering Asset Management, 1(2), 153 - 171.

[36] Maletič, D., Maletič, M., Al-Najjar, B., Gomišček, B. (2014). The role of maintenance in improving company's competitiveness and profitability: A case study in a textile company. Journal of Manufacturing Technology Management, 25(4), 441-456. Doi:10.1108/JMTM-04-2013-0033

[37] Dahlgaard, J.J., Kristensen, K., Kanji, G. (1998) Fundamentals of Total Quality Management, Chapman \& Hall, London.

[38] Alsyouf, I. (2009). Maintenance practices in Swedish industries: Survey results. International Journal of Production Economics, 121(1), 212-223.

[39] Dahlgaard-Park, S.M., Dahlgaard, J.J. (2010). Organizational learnability and innovability: A system for assessing, diagnosing and improving innovations. International Journal of Quality and Service Sciences, 2(2), $153-174$.

[40] Al-Najjar, B. (2002). Company's business and competitiveness enhancement: A model of integrated vibration-based maintenance impact on company's effectiveness. Proceedings of COMADEM 2002: 15th International Congress on Condition Monitoring and Diagnostic Engineering Management', Birmingham, UK, 2-4 September 2002, pp. 238248.

[41] Crespo Márquez, A., Moreu de León, P., Gómez Fernández, J.F., Parra Márquez, C., López Campos, M. (2009). The maintenance management framework: A practical view to maintenance management. Journal of Quality in Maintenance 
Engineering, 15(2), 167-178.

[42] Pacaiova, H., Nagyova, A., Namesanska, J., Grencik, J. (2013). Systematic approach in maintenance management improvement. International Journal of Strategic Engineering Asset Management, 1(3), 228-237.

[43] Berges, L., Galar, D., Stenström, C. (2013). Qualitative and quantitative aspects of maintenance performance measurement: a data fusion approach. International Journal of Strategic Engineering Asset Management, 1(3), 238 - 252.

[44] Sheikhalishahi, M., Pintelon, L., Azadeh, A. (2016). Human Factors in Maintenance: A review. Journal of Quality in Maintenance Engineering, 22(3), 218-237.

[45] Al-Najjar, B. (2007). The lack of maintenance and not maintenance which costs: A model to describe and quantify the impact of vibration-based maintenance on company's business. International Journal of Production Economics, 107(1), 260-273.

[46] Maletič, D., Maletič, M., Al-Najjar, B., Gotzamani, K., Gianni, M., Kalinowski, T. B., Pačaiová, H., Nagyová, A., Gomišček, B. (2016). The role of contingency factors in physical asset management: An empirical examination. In: Euromaintenance 2016 proceedings: Paper presented at Euromaintenance 2016 (pp. 93-99)

[47] Maletič, D. (2015). Interaction between Quality Management, Production and Maintenance Performance, PhD thesis, Faculty of Organizational Sciences, University of Maribor, Kranj.

\section{Biographical notes}

Damjan Maletic, PhD., is an Assistant Professor at the Faculty of Organizational Sciences, University of Maribor. His research activities are mainly devoted to the fields of physical asset management, maintenance and quality management. Currently one main area of his research has focused on studying the relationship between physical asset management practices and organizational performance. He holds a bachelor's degree in Wood Science and Technology (University of Ljubljana) and Organization (University of Maribor).

Matjaž Maletič, PhD., is an Assistant Professor at the Faculty of Organizational Sciences, University of Maribor. His main research interest concerns the quality management, corporate sustainability, integration of quality management and sustainability, exploitation-exploration paradigm and organizational performance. He holds a Bachelor's Degree in Wood Science and Technology (University of Ljubljana, Biotechnical Faculty), a Bachelor's Degree in Organization (University of Maribor, Faculty of Organizational Sciences) and PhD Degree in Quality Management (University of Maribor, Faculty of Organizational Sciences).

Boštjan Gomišček, PhD ., is professor at Faculty of Business, University of Wollongong in Dubai, UAE. He is predominantly engaged in the following research fields: quality management, sustainable quality management and maintenance management. He has published several research papers in international journals and presented his research work at numerous national and international conferences. 